\title{
Measuring clinically significant outcomes - LDQ, CORE-10 and SSQ as dimension measures of addiction
}

\author{
Duncan Raistrick, ${ }^{1,2}$ Gillian Tober, ${ }^{1,2}$ Jenny Sweetman, ${ }^{1}$ Sally Unsworth, ${ }^{1}$ Helen Crosby, ${ }^{1}$ Tom Evans $^{1}$
}

Psychiatric Bulletin (2014), 38, 112-115, doi: 10.1192/pb.bp.112.041301

${ }^{1}$ Leeds Addiction Unit; ${ }^{2}$ University of Leeds

Correspondence to Duncan Raistrick (d.raistrick@nhs.net)

First received 22 Aug 2013, final revision 10 Sep 2013, accepted 16 Sep 2013

(C) 2014 The Royal College of

Psychiatrists. This is an open-access article published by the Royal College of Psychiatrists and distributed under the terms of the Creative Commons Attribution License (http:// creativecommons.org/licenses/by/ 3.0), which permits unrestricted use, distribution, and reproduction in any medium, provided the original work is properly cited.

\begin{abstract}
Aims and method To determine values for reliable change and clinically significant change for the Leeds Dependence Questionnaire (LDQ) and Social Satisfaction Questionnaire (SSQ). The performance of these two measures with the Clinical Outcomes in Routine Evaluation (CORE-10) as three dimension measures of addiction was then explored.
\end{abstract}

Results The reliable change statistic for both LDQ and SSQ was $\geqslant 4$; the cut-offs for clinically significant change were LDQ $\leqslant 10$ males, $\leqslant 5$ females, and SSQ $\geqslant 16$. There was no overlap of $95 \% \mathrm{Cls}$ for means by gender between 'well-functioning' and pre- and post-treatment populations.

Clinical implications These data enable the measurement of clinically significant change using the LDQ and SSQ and add to the evidence for the performance of the LDQ, CORE-10 and SSQ as dimension measures of addiction. The CORE-10 and SSQ can be used as treatment outcome measures for mental health problems other than addiction.

Declaration of interest This paper is part of independent research funded by the National Institute for Health Research (NIHR) through the NIHR Collaboration in Leadership for Applied Health Research and Care for Leeds, York and Bradford. The views expressed are those of the authors and not necessarily those of the NHS, NIHR or the Department of Health. The NIHR had no role in the study design, collection, analysis or interpretation of the data, writing the presentation, or the decision to submit the poster for dissemination. The Local Research Ethics Committees reference: 10/H1306/38.
Transparency of the outcomes achieved by services is one means of driving quality improvement; ${ }^{1}$ however, if outcomes are to influence policy and commissioning, then the measures used must be up to the task. The Health Technology Assessment by Fitzpatrick ${ }^{2}$ describes three types of outcome measure:

- generic measures are concerned with an overarching concept, in this case health

- dimension measures are about a particular aspect of health, in this case addiction

- specific condition measures are focused on a diagnostic category, for example anxiety or personality disorder.

A rational approach to assessing treatment outcome is to combine a judicious mix of generic, dimension and condition-specific scales, which must be robust as judged by a quality framework. ${ }^{3}$

Addiction is usually assessed across three key dimensions: dependence, psychological well-being and social well-being, ${ }^{4}$ which are reflected in the scale selection. ${ }^{5}$ The Leeds Dependence Questionnaire (LDQ) measures dependence on psychoactive substances; ${ }^{6}$ it is a 10-item scale derived from a psychological understanding of dependence, reflects ICD-10, ${ }^{7}$ and has extensive and independent validation. ${ }^{8-12}$ The Social Satisfaction Questionnaire (SSQ) measures satisfaction with social circumstances $^{13}$ and is an 8 -item scale adapted from the Social Problems Questionnaire. ${ }^{14}$ Clinical Outcomes in Routine Evaluation (CORE-10 version) is a 10-item scale which measures psychological well-being; its psychometric properties have been comprehensively investigated and reported. $^{15}$ This paper reports on the psychometric properties of the LDQ and SSQ required to estimate clinically significant change ${ }^{16,17}$ and then applies these, with CORE-10, to a clinical sample.

\section{Method}

\section{Well-functioning population}

A 'well-functioning' sample is required to calculate a cut-off for clinically significant change. We set a timescale within which to recruit an opportunistic sample from the local 
Table 1 Demographic details for functional and clinical groups

\begin{tabular}{lccccc} 
& \multicolumn{2}{c}{ Functional population, $n=817$} & & \multicolumn{2}{c}{ Clinical population, $n=653$} \\
\cline { 2 - 3 } & Male & Female & & Male & Female \\
\hline Gender, \% & 25.1 & 74.9 & & 52.4 & 47.6 \\
\hline Age, years: mean (s.d) & $38.6(8)$ & $36.3(11.4)$ & & $43.7(10.8)$ & $41.7(11.2)$
\end{tabular}

Table 2 Mean scores for the Leeds Dependence Questionnaire (LDQ) and Social Satisfaction Questionnaire (SSQ)

\begin{tabular}{|c|c|c|c|c|c|c|}
\hline & \multirow{2}{*}{\multicolumn{2}{|c|}{ Functional population, $n=817$}} & \multicolumn{4}{|c|}{ Clinical population, $n=653$} \\
\hline & & & \multicolumn{2}{|c|}{ Male } & \multicolumn{2}{|c|}{ Female } \\
\hline & Male & Female & Pre-treatment & Post-treatment & Pre-treatment & Post-treatment \\
\hline LDQ, mean $(95 \% \mathrm{Cl})$ & $4.3(3.5-5.0)$ & $2.5(2.2-2.8)$ & $17.8(16.9-18.7)$ & $8.6(7.7-9.5)$ & $10.9(9.8-12.0)$ & $4.2(3.6-4.9)$ \\
\hline SSQ, mean $(95 \% \mathrm{Cl})$ & $18.6(16.9-20.3)$ & $19.1(18.4-19.8)$ & $13.8(13.2-14.4)$ & $15.3(14.7-15.9)$ & $16.0(15.4-16.6)$ & $17.3(16.7-17.9)$ \\
\hline
\end{tabular}

health service and the local university. The target was to equal in number the clinical sample; in the event, 817 individuals were recruited. Participants were invited to take part in the study by email sent through their National Health Service (NHS) or university workplace (and so response rates are not known) with a link to submit responses to the LDQ and SSQ online. Potential participants were given information about the study and understood that taking part was voluntary. They were invited to provide an email address if they wished to be entered into a prize draw for $£ 50$ vouchers. The study data and the email addresses for the prize draw were entered into separate, unconnected databases. Procedures were negotiated with a local research ethics committee. When participants logged on to the survey, the first screen asked them to disclose their age, gender, marital status, employment status, alcohol use (self-identified as 'abstainer', 'occasional drinker' or 'regular drinker') and drug use ('yes' or 'no'). On subsequent screens they completed the LDQ and SSQ. Completion of the LDQ and SSQ was considered valid with up to two missing values within each scale; missing values were scored as the mean of the completed scores.

\section{Dysfunctional (clinical) population}

A clinical sample of 653 records was extracted from the local specialist addiction service clinical database; records were selected if age, gender, pre-treatment and paired post-treatment LDQ, SSQ and CORE-10 scores were available. Fifty-six per cent were in their first treatment episode, $24 \%$ were in the second and $20 \%$ the third or more. Completion of the LDQ, CORE-10 and SSQ was considered valid with up to two missing values within each scale. Posttreatment records were obtained between 3 and 12 months. Leeds Dependence Questionnaire and SSQ values for the 'well-functioning' group, and CORE-10 values taken from the published data ${ }^{15}$ were used to determine whether reliable or significant change occurred pre- to posttreatment. We have mirrored the methodology applied to evaluating the psychometrics of CORE-10 for the LDQ and SSQ so as to harmonise the three as dimension measures of addiction.

\section{Results}

In the 'well-functioning' sample, $6.6 \%$ described themselves as abstainers from alcohol and were excluded from further analysis; $52.0 \%$ described themselves as occasional drinkers and $41.4 \%$ as regular drinkers; $9.4 \%$ said they used illicit drugs. The age, gender and mean scores of the LDQ and SSQ are shown in Tables 1 and 2. The reliable change scores are LDQ 3.5 (rounded to 4) and SSQ 4.3 (rounded to 4). There are no overlaps in the confidence intervals for the means of the LDQ and SSQ in the 'well-functioning' and 'dysfunctional' (clinical) populations either pre- or post-treatment compared by gender.

The cut-off points for the probability of belonging to the 'well-functioning' group are: $\mathrm{LDQ}$ (lower score is better) male 9.8 (rounded to $\leqslant 10$ ), female 5.0 (rounded to $\leqslant 5$ ); SSQ (higher score is better) male 15.3, female 17.2 (rounded to $\geqslant 16$ for both genders). Table 3 presents the percentage of those in treatment meeting the four outcome categories: reliable deterioration, no change, reliable improvement, and reliable improvement with clinically significant change. We investigated the effects of age and treatment episode on the achievement of clinically significant improvement. For three age groups $(<35,35-49, \geqslant 50$ years old $)$ the proportions achieving clinically significant change were: LDQ $33.6 \%$, $42.4 \%$, 51.4\%; CORE-10 24.6\%, 26.5\%, 33.3\%; SSQ $17.0 \%$, $26.4 \%, 20.1 \%$. For episode categories (1st, 2nd, 3rd or more) the proportions achieving clinically significant change were: LDQ $44.0 \%$, 35.5\%, 46.6\%; CORE-10 28.5\%, 27.3\%, 26.2\%; SSQ $22.6 \%, 21.3 \%, 22.9 \%$. The baseline and follow-up correlations are LDQ and CORE-10: 0.65 and 0.61; LDQ and SSQ: -0.39 and -0.30 ; CORE-10 and SSQ: -0.47 and -0.56 .

\section{Discussion}

Jacobson \& $\operatorname{Truax}^{16}$ and Jacobson et $a l^{17}$ have described three statistical methods for determining whether change after an episode of treatment is clinically significant. They conceptualise the clinical population as 'dysfunctional' and the aim of treatment as bringing individuals within the bounds of a 'well-functioning' population. They describe the 
Table 3 Outcomes for dimension measures LDQ, CORE-10 and SSQ

$\%$

\begin{tabular}{|c|c|c|c|c|c|c|c|c|c|c|c|c|c|}
\hline & \multirow[b]{2}{*}{$n$} & \multicolumn{3}{|c|}{ Reliable deterioration } & \multicolumn{3}{|c|}{ No reliable change } & \multicolumn{3}{|c|}{ Reliable improvement } & \multicolumn{3}{|c|}{$\begin{array}{l}\text { Reliable and clinically } \\
\text { significant improvement }\end{array}$} \\
\hline & & LDQ & $\begin{array}{l}\text { CORE- } \\
10\end{array}$ & SSQ & LDQ & $\begin{array}{l}\text { CORE- } \\
10\end{array}$ & SSQ & LDQ & $\begin{array}{l}\text { CORE- } \\
10\end{array}$ & SSQ & LDQ & $\begin{array}{l}\text { CORE- } \\
10\end{array}$ & SSQ \\
\hline \multicolumn{14}{|l|}{ Gender } \\
\hline Male & 270 & 4.8 & 4.8 & 14.7 & 25.9 & 46.0 & 54.2 & 69.3 & 49.2 & 31.8 & 50.4 & 26.8 & 23.7 \\
\hline Female & 241 & 4.6 & 9.6 & 13.6 & 44.0 & 45.4 & 59.1 & 51.4 & 45.0 & 29.6 & 33.6 & 28.8 & 22.9 \\
\hline All & 511 & 4.7 & 7.0 & 14.2 & 34.4 & 45.7 & 56.5 & 60.9 & 47.2 & 30.7 & 42.5 & 27.7 & 23.3 \\
\hline \multicolumn{14}{|l|}{ Substance } \\
\hline Alcohol & 319 & 3.4 & 3.1 & 11.5 & 22.9 & 38.4 & 57.5 & 73.7 & 58.5 & 31.0 & 51.4 & 34.7 & 23.9 \\
\hline Heroin & 68 & 4.4 & 13.2 & 10.3 & 48.5 & 48.5 & 51.5 & 47.1 & 38.2 & 38.2 & 35.3 & 19.1 & 29.4 \\
\hline Methadone & 49 & 0 & 12.2 & 24.0 & 93.9 & 75.5 & 62.0 & 6.1 & 12.2 & 14.0 & 4.1 & 12.2 & 12.0 \\
\hline Stimulants & 22 & 9.1 & 13.6 & 9.1 & 45.5 & 54.5 & 59.1 & 45.5 & 31.8 & 31.8 & 27.3 & 13.6 & 22.7 \\
\hline
\end{tabular}

CORE-10, Clinical Outcomes in Routine Evaluation; LDQ, Leeds Dependence Questionnaire; SSQ, Social Satisfaction Questionnaire.

method for determining a cut-off score for a scale which defines whether an individual is more likely to belong to the 'well-functioning' rather than 'dysfunctional' population as the least arbitrary of the three proposed methods. For clinically significant change to occur, a second criterion reliable change - which takes account of measurement error must also be achieved. The reliable change value is the minimum improvement post-treatment which yields a $90 \%$ probability that change is not due to variations in measurement. Reliable change values are calculated from a post-treatment population; ${ }^{15}$ clinically significant cut-off scores are calculated from both 'well-functioning' and pre-treatment populations. ${ }^{15}$

A general population sample might be the ideal 'wellfunctioning' sample but recruitment would be difficult and costly. The population recruited here, university and NHS staff, is not representative of the general population. There is an overrepresentation of females, which could be accounted for by a combination of factors: female gender bias in internet surveys, ${ }^{18}$ ease of access to the internet, interest in the survey subject matter, and recruiting from predominantly female workforces. However, the patterns of reported drinking and dependence scores are as expected. The gender imbalance is immaterial since calculations are made separately for males and females. Dependence scores varied with different levels of reported substance use: mean LDQ for abstainers of both alcohol and drugs was 0.37, hence abstainers were excluded from the analyses. The CORE-10 and SSQ scores were less affected but participants with illicit drug use had consistently higher CORE-10 scores.

It is not possible to achieve clinically significant improvement if the pre-treatment score is already within the range of the 'well-functioning' population. In the clinical sample the SSQ pre-treatment mean is high, indicating that even the clinic population has a general satisfaction with their social circumstances, thus making clinically significant change less likely. Dissatisfaction was most commonly expressed with two SSQ items, employment and finance. There are no overlaps in the confidence intervals for the means of the LDQ and SSQ, compared by gender, between the 'well-functioning', pre-treatment and post-treatment populations, suggesting both instruments have the capacity to discriminate between these populations and are sensitive to change.

When applied to the clinical population, the LDQ scores showed most improvement, which might be expected in an addiction treatment service. Individuals with an alcohol problem improved more than those with heroin or other drug problems; drinkers were predominantly male (61.5\%), whereas heroin users were predominantly female (55.8\%). Where methadone was the main problem drug (typically started as a substitute prescription), change was much less likely than for other substances across all three measures. We looked at outcomes by age group and by episode of treatment - the results are varied and difficult to interpret. The relationship between the LDQ, CORE-10 and $\mathrm{SSQ}$ is interesting. Deterioration is more common for CORE-10 and SSQ, which is a well-recognised phenomenon clinically - abstinence or control over substance misuse exposes individuals to the consequences of their substance use and this is commonly expressed as psychological distress and dissatisfaction with social circumstances. These negative experiences reflect the real world and should not necessarily be taken as symptoms of mental illness. Newly abstinent drinkers or, more commonly, drug users may also experience a psychological insecurity which, again, may be expressed in high CORE-10 and low SSQ scores. The precision of short scales is limited and is a tradeoff against the benefits of tools suitable for routine clinical use $^{19}$ - shorter scales need more careful interpretation of results. The combined dimension measures LDQ, CORE-10 and SSQ seem to work well as tools helping better to understand the process of addiction treatment.

The dimensions chosen have consistently been evidenced as important elements of addiction. Dependence is a predictor of treatment outcomes ${ }^{20,21}$ which tends to reduce early in treatment, ${ }^{22}$ and so dependence works well as a feedback tool for practitioners. Equally, social satisfaction is important: the benefits of supportive relationships in long-term recovery from alcohol problems have been well documented ${ }^{23-26}$ and the idea of social support to aid 'recovery' is long established. ${ }^{27,28}$ Positive social circumstances play a role in protecting individuals from risks such as depressive affect, psychological distress and stressful life events. ${ }^{29}$ This paper adds to the evidence that 
the LDQ, CORE-10 and SSQ are appropriate measures and perform well as dimension measures of addiction.

\section{About the authors}

Duncan Raistrick is a consultant addiction psychiatrist and lead clinician, Leeds Addiction Unit, and an associate senior lecturer, University of Leeds; Gillian Tober is a consultant addiction psychologist and clinical service manager, Leeds Addiction Unit, and an associate senior lecturer, University of Leeds; Jenny Sweetman is a research practitioner, Sally Unsworth is a research assistant, Helen Crosby is a research coordinator and Tom Evans was a data analyst at the time of the study, all at Leeds Addiction Unit.

\section{References}

1 Humpreys K, McLellan T. A policy-oriented review of strategies for improving the outcomes of services for substance use disorder patients. Addiction 2011; 106: 2058-66.

2 Fitzpatrick R, Davey C, Buxton M, Jones D. Evaluating patient-based outcome measures for use in clinical trials. Health Technol Assess 1998; 2: $1-74$.

3 National Institute for Mental Health in England. Outcomes Compendium. Barts and The London School of Medicine and Deanery, 2009.

4 Raistrick DS, Heather N, Godfrey C. Assessment and measuring treatment outcomes. In Review of the Effectiveness of Treatment for Alcohol Problems: 69-78. National Treatment Agency, 2006.

5 Raistrick D, Tober G, Godfrey C, Parrott S. Treatment as usual. In Responding to Drug Misuse: Research and Policy Priorities in Health and Social Care (ed. S MacGregor): 40-52. Routledge, 2010.

6 Raistrick D, Bradshaw J, Tober G, Weiner J, Allison J, Healey C. Development of the Leeds Dependence Questionnaire (LDQ): a questionnaire to measure alcohol and opiate dependence in the context of a treatment evaluation package. Addiction 1994; 89: 563-72.

7 World Health Organization. ICD-10 Classifications of Mental and Behavioural Disorder: Clinical Descriptions and Diagnostic Guidelines. WHO, 1999.

8 Heather N, Raistrick D, Tober G, Godfrey C, Parrott S. Leeds Dependence Questionnaire: new data from a large sample of clinic attenders. Addict Res Theory 2001; 9: 253-69.

9 Paton-Simpson G, MacKinnon S. Evaluation of the Leeds Dependence Questionnaire (LDQ) for New Zealand in Research Monograph Series: No 10. Alcohol Advisory Council of New Zealand, 1999.

10 Lennings CJ. Evaluation of the Leeds Dependence Questionnaire. J Child Adolesc Subst Abuse 1999; 8: 73-87.

11 Ford P. An evaluation of the Dartmouth Assessment of Lifestyle Inventory and the Leeds Dependence Questionnaire for use among detained psychiatric inpatients. Addiction 2003; 98: 111-18.

12 Kelly JF, Magill M, Slaymaker V, Kahler C. Psychometric validation of the Leeds Dependence Questionnaire (LDQ) in a young adult clinica sample. Addict Behav 2010; 35: 331-6.
13 Raistrick D, Tober G, Heather N, Clark JA. Validation of the Social Satisfaction Questionnaire for outcome evaluation in substance use disorders. Psychiatr Bull 2007; 31: 333-6.

14 Corney $\mathrm{RH}, \mathrm{Clare} \mathrm{AW}$. The construction, development and testing of a self-report questionnaire to identify social problems. Psychol Med 1985; 15: $637-49$.

15 Connell J, Barkham M. CORE-10 User Manual, Version 1.1. CORE System Trust, CORE Information Management Systems, 2007.

16 Jacobson NS, Truax P. Clinical significance: a statistical approach to defining meaningful change in psychotherapy research. J Consult Clin Psychol 1991; 59: 12-9.

17 Jacobson NS, Roberts LJ, Berns SB, McGlinchey B. Methods for defining and determining clinical significance of treatment effects: description, application, and alternatives. J Consult Clin Psychol 1999; 67: 300-7.

18 Cull WL, O'Connor KG, Sharp S, Tang S-FS. Response rates and response bias for 50 surveys of paediatricians. Health Serv Res 2005; 40: 213-26.

19 Barkham M, Bewick B, Mullin T, Gilbody S, Connell J, Cahill J, et al. The CORE-10: a short measure of psychological distress for routine use in the psychological therapies. Couns Psychother Res 2013; 13: 3-13.

20 Adamson SJ, Sellman JD, Frampton CMA. Patient predictors of alcohol treatment outcomes: a systemic review. J Subst Misuse Treat 2009; 36: 75-86.

21 Gibbs L, Flanagan J. Prognostic indicators of alcoholism treatment outcome. Int J Addict 1977; 12: 1097-141.

22 Tober GW. The nature and measurement of change in substance dependence [PhD thesis]. University of Leeds, 2000.

23 Moos RH, Moos BS. The process of recovery from alcoholism. III. Comparing functioning in families of alcoholics and matched control families. J Studies Alcohol 1984; 45: 111-8.

24 Havassy BE, Hall SM, Wasserman DA. Social support and relapse: commonalities among alcoholics, opiate users and cigarette smokers. Addict Behav 1991; 16: 235-46.

25 Finney JW, Moos RH. The long-term course of treated alcoholism. II: Predictors and correlates of 10-year functioning and mortality. J Stud Alcohol 1992; 53: 142-53.

26 Humphreys K, Moos RH, Cohen C. Social and community resources and long-term recovery from treated and untreated alcoholism. J Stud Alcohol 1997; 58: 231-8.

27 Galanter M. Network therapy for addiction: a model for office practice. Am J Psychiatry 1993; 150: 28-36.

28 Havassy BE, Wasserman DA, Hall SM. Social relationships and abstinence from cocaine in an American treatment sample. Addiction 1995; 90: 699-710.

29 Brewer DD, Catalano RF, Haggerty K, Gainey RR, Fleming CB. A metaanalysis of predictors of continued drug use during and after treatment for opiate addiction. Addiction 1998; 93: 73-92. 